\title{
La causa de pedir en el juicio de precario (Corte de Apelaciones de Valparaíso)
}

\author{
Comentario de Ignacio Rostión Casas
}

Valparaíso, diecisiete de julio del año dos mil doce.

\section{VISTOS Y TENIENDO PRESENTE.}

Primero: Que la actora se alza en contra de la sentencia de primera instancia pues estima que pese a que en el motivo octavo de la sentencia que se impugna el señor Juez de la instancia le consta con la prueba documental rendida que ella es dueña efectivamente del Lote A, Población Araya, de la ciudad de Quilpué, rechaza la demanda de precario, (no se entiende, lo cambie, pero ve bien el tema de precario, porque ahí no queda muy claro) por cuanto su parte no acredito que el predio objeto de la litis, individualizado en el libelo de fs. 4, esto es, en calle Buenos Aires N ${ }^{\circ} 1619$, corresponda al Lote A de la Población referida. Agrega, que en virtud de lo dispuesto en los artículos 207 y 348 del Código de Procedimiento Civil, acompañara en la oportunidad procesal pertinente, certificado de numeración domiciliaria, de 12 de abril del año en curso, expedido por la Dirección de Obras Municipales de la I. Municipalidad de Quilpué con la finalidad de comprobar fehacientemente que el domicilio que antes se individualiza como Lote A, Población Araya, de calle Buenos Aires No 1619, Quilpué, actualmente corresponde a la dirección del lote mencionado, respecto del cual es su propietario. En definitiva, solicita se acoja la demanda de comodato precario y que se condene al demandado de autos a la devolución del inmueble indicado, al ser el dueño exclusivo y excluyente de la propiedad ubicada en calle Buenos Aires 1619, que corresponde al Lote A de la Población Araya, como se demuestra en el certificado de numeración domiciliaria que acompañara en la oportunidad procesal que corresponda.

SEgundo: Que previo a resolver la cuestión debatida es necesario tener presente que en el contrato de comodato se estipula expresamente que el comodatario (lo cambie), es decir, la persona a quien se entrega la cosa, debe devolverla en un plazo determinado, estableciendo el uso que ésta debe hacer de ella, estamos frente al contrato de comodato común. En cambio, si no se fija plazo de restitución ni tampoco se determina el uso que el comodatario va a hacer de la cosa, el contrato se denomina "comodato precario" (artículos 2174 , 2194 y 295 inciso $1^{\circ}$ del Código Civil). A su vez, el simple precario contemplado en el inciso $2^{\circ}$ del artículo 2195 del cuerpo de leyes precedentemente citado, está constituido solo por una situación de hecho, en que la detentación material de la cosa está configurada, frente al dueño, por la ignorancia o mera tolerancia de éste. 
Tercero: Que en la especie, si bien el actor denomina a su acción "comodato precario", no es menos cierto que la basa en que el demandado ocupa una propiedad de su dominio, "por su mera tolerancia" y en esta afirmación fundamenta su pretensión. Además, apoya su demanda en el artículo 2195 del Código Civil. Conforme a lo que se anota se tramitó y falló la causa.

CuARto: Que la circunstancia de haber llamado el demandante a su acción "comodato precario" no puede alterar la sustancia del juicio, puesto que las cosas son por lo que concierne a su naturaleza y no por el nombre que se les dé.

Quinto: Que de la simple lectura de la demanda formulada en los autos, queda en evidencia que, como antes se dijo, se funda en hechos que constituyen específicamente la acción de precario que contempla el artículo 2195, inciso $2^{\circ}$, del Código Civil, toda vez que es la situación allí regulada en la que calzan los hechos en que se basa, lo que hace que el yerro del actor en la denominación de su acción resulte irrelevante. Ninguna mención se hace en la demanda en comento a hechos que pudieran constituir un "comodato común" o un "comodato precario".

Sexto: Que en cuanto al motivo por el cual se desestima la demanda de fs. 4 y siguientes se dirá que con los documentos acompañados en el primer otrosí de fs. 5 unido al certificado de numeración domiciliaria de fs. 43 expedido por la Dirección de Obras Municipales de la I. Municipalidad de Quilpué de 12 de abril del año en curso, debidamente acompañado, no objetado en la que consta que la propiedad ubicada en calle Buenos Aires, Villa Araya de Quilpué corresponde al lote $\mathrm{N}^{\mathrm{o}}$ "A" que corresponde a su vez, al domicilio que ocupa el demandado, donde fue notificado (fs. 15), en consecuencia la actora ha acreditado su derecho de propiedad respecto del inmueble antes individualizado.

SEPTimo: Que por otra parte, se ha acreditado que el demandado es un simple detentador de la propiedad de la demandante, toda vez que no ha acompañado título alguno, que justifique la tenencia del inmueble de dominio del actor. En otras palabras, la ocupación del inmueble por parte del demandado se ha fundado en la mera tolerancia de la demandante.

Por estas consideraciones y visto, además de lo establecido en los artículos 1698 y 2195 del Código Civil, 186 y siguientes del Código de Procedimiento Civil, SE REVOCA la sentencia apelada de diecinueve de marzo del año dos mil doce, escrita de fojas 25 a 26, y en su lugar, se declara: que ha lugar a la demanda de precario interpuesta en lo principal de fs. de fs. 4 por don Benito Alberto Guerra Gamboa en contra de Esteban Mauricio Reyes Canave; en consecuencia, el inmueble deberá ser restituido dentro de tercero día de ejecutoriada la sentencia, bajo apercibimiento de ser lanzado con el auxilio de la fuerza pública, con costas de recurso.

Notifíquese, regístrese y devuélvase en su oportunidad. 
Redacción de la Ministra señora Inés María Letelier Ferrada.

$\mathrm{N}^{\circ}$ Civil-987-2012.

Pronunciada por las Ministros Sra. María Angélica Repetto García, Sra. Inés María Letelier Ferrada y abogado integrante Sr. Germán Lührs Antoncich.

\section{COMENTARIO}

Dilucidar si el Tribunal que conoce sobre una pretensión de comodato o comodato precario puede cambiar la calificación jurídica a la de precario ha resultado en nuestro derecho una cuestión altamente compleja. La causa petendi en los juicios de precario cobra una importancia superior debido a que aquí se diferencia entre las dos situaciones, contractual y de hecho, que comprende el art. 2195 CC (el comodato precario y el precario).

La diferenciación en la discusión es relevante, ya que, si los tribunales estiman que la causa de pedir está constituida solo por los hechos expuestos, se podría cambiar por el tribunal de oficio la calificación de una demanda que se inicia por comodato precario para terminar fallándose como un precario a secas. Esta postura desde la perspectiva procesal es la correcta, porque la posición que le corresponde al juez debe ser adquirida a base de los hechos que exponen los intervinientes. Pero si por el contrario creyésemos que la visión apropiada sobre la causa de pedir está constituida conjuntamente por los hechos y por las normas invocadas, quien haya demandado de comodato o comodato precario no podría tratar de cambiar su pretensión y utilizar los beneficios del precario.

Sobre el punto expuesto la mayoría de la jurisprudencia chilena que se ha pronunciado en juicio de precario insiste en afirmar que la causa de pedir del actor descansa en los hechos narrados, y que, por ende, no existe ningún inconveniente en que el juez modifique de oficio la calificación jurídica que hacen los litigantes. Es así como el demandante podría pretender un comodato precario y el Tribunal decidir basándose en los requisitos constitutivos del precario. Así es como la Corte de Apelaciones de Valparaíso no tubo temor en señalar "Que la circunstancia de haber llamado el demandante a su acción "comodato precario" no puede alterar la sustancia del juicio, puesto que las cosas son por lo que concierne a su naturaleza y no por el nombre que se les dé”. Sobre la decisión del Tribunal de Apelación solo cabe señalar que se ha encargado de cerrar una corriente jurisprudencial que ya se había hecho sentir en otros casos, como por ejemplo, Sociedad Agrícola Santa Bárbara con I. Municipalidad de Codegua donde se establece "Que el demandante yerre en la denominación específica de su acción, y solo en ello, es irrelevante”, ${ }^{1}$ en Yáñez y otros con Yáñez, donde el Tribunal señaló que "La denominación que el demandante asigne en la suma de su libelo a la acción, no es lo determinante, y menos cuando el uso todavía permita, por las razones ya señaladas, una confusión explicable entre las dos instituciones. Lo central está, en cambio, en qué

${ }^{1}$ Corte de Apelaciones de Rancagua, 31 mayo 2002, Rol No 18528, LegalPublishing No 24586, cons. $1^{\circ}$ (redacción del Ministro Raúl Mera). 
hechos relate el actor en su demanda"2, y así otro caso como Pinninghoff González con Araya del Campo y Rivas Pinninghoff, "si bien la demanda presentada al tribunal fue individualizada como de 'comodato precario', lo cierto es que de acuerdo con el contenido del libelo y la disposición legal invocada como fundamento, se infiere que la acción ejercida es la de 'precario' y sobre ella versará la decisión del Tribunal”3.

Por su parte, la acotada literatura civil que se ha escrito sobre la acción de precario ha señalado que siendo el comodato y el comodato precario acciones personales, la causa de pedir es "precisamente ese contrato y la consiguiente obligación de restituir la cosa prestada que le impone al comodatario (...), tratándose de la acción de precario la causa de pedir es el dominio que el actor invoca para obtener la restitución de la cosa que el demandado ocupa, sin título y por mera tolerancia o ignorancia" ${ }^{4}$. Sofía Vergara ha señalado que "la causa de pedir es la reunión copulativa de los requisitos contenidos en el artículo 2195 inciso segundo del Código Civil y, el pedido, es la restitución de la cosa, para lo cual se aplica el procedimiento sumario. El precario es una situación de hecho que se enfrenta a un derecho; de esta manera, son materias ajenas a este tipo de juicios los asuntos de dominio o posesión que pueden existir o derivar de la causa, los que deberán verse en otro procedimiento"s.

La postura defendida sí ha sido controvertida en juicio, y el medio ha sido el recurso de casación por ultra petita, al considerar los litigantes que el Tribunal ha fallado más allá de lo solicitado al tomar la atribución de oficio de cambiar la denominación de la acción pretendida, como ocurrió en los casos Alvarado con Hernández ${ }^{6}$, Leal y Hermosilla con Levio ${ }^{7}$ y Carrasco Bravo con Riveros De la Puente ${ }^{8}$, todos estos, donde el correspondiente recurso de casación fue desechado por distintos motivos.

Siendo este el cuadro sobre el funcionamiento de la causa de pedir en la acción de precario, donde ha imperado una visión procesal, es la explicitación correcta de los hechos lo que determina en última medida cuál es la verdadera intención de la parte demandante. Así, se puede concluir que el cambio en la designación de la acción de comodato precario a precario, comúnmente realizada por los jueces, es manifestación del principio de iura novit curia.

${ }^{2}$ Juzgado de Letras de Pichilemu, 3 junio 2010, Rol No 5685-09, Legal Publishing No 48227, cons. $8^{\circ}$ y $9^{\circ}$ (redacción de la jueza Catherine Norambuena).

${ }^{3}$ Corte Suprema, 2 enero 2006, Rol No 1446-2004, Legal Publishing No 33573, cons. $7^{\circ}$.

${ }^{4}$ Halabí, Fuad y Saffirio, Carlos (1996), La acción de precario ante la doctrina y la jurisprudencia, Editorial Jurídica ConoSur, 17.

${ }^{5}$ Vergara Aldunate, Sofía (1991), El comodato precario y el simple precario ante el derecho y la jurisprudencia, Editorial Jurídica ConoSur, 185-186.

${ }^{6}$ Corte Suprema, 18 diciembre 2000, Rol No 10277-99, Legal Publishing $\mathrm{N}^{\circ} 17754$, cons. $4^{\circ}$ y $5^{\circ}$ (redacción del abogado integrante Manuel Daniel).

${ }^{7}$ Corte Suprema, 17 julio 2001, Rol N ${ }^{\circ}$ 3923-2000, Legal Publishing N ${ }^{\circ} 22276$, cons. $7^{\circ}$ y $8^{\circ}$ (redacción del ministro Salvador Jordán).

${ }^{8}$ Corte Suprema, 25 septiembre 2008, Rol No 5657-2007, Legal Publishing $\mathrm{N}^{\circ} 39879$, cons. $6^{\circ}$ (redacción del abogado integrante Óscar Carrasco). 